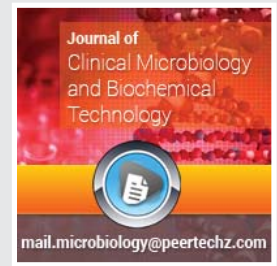

\section{Nanovesicles of cholesterol-}

\section{free enable malignant tumor- specific magnetic resonance}

\section{imaging}

\section{Zhilin Zhang', Guochao Nie ${ }^{1-3 *}$, Yunting Deng', Lonli Song', Wangqiang $\mathrm{Wei}^{4}$, Huali $\mathrm{Li}^{4}$, Mengfei $\mathrm{Lu}^{4}$, Dongxian Qin ${ }^{5}$ and Yulin Yan ${ }^{6 *}$}

${ }^{1}$ School of Physics and telecommunications Engineering, Yulin Normal University, Yulin 537000, China ${ }^{2}$ Guangxi Key Laboratory of Agricultural Resources Chemistry and Biotechnology, Yulin 537000, China ${ }^{3}$ China-Ukraine Joint Research Center for Nano Carbon Black, China

${ }^{4}$ School of Chemistry and Food Science, Yulin Normal University, China

${ }^{5}$ School of Biology and Pharmaceuticals, Yulin Normal University, China

${ }^{6}$ Department of Dermatology and Venereology, First Affiliated Hospital of Guangxi Medical University, Nanning, 530022, China
Received: 27 January, 2021

Accepted: 09 February, 2021

Published: 10 February, 2021

*Corresponding authors: Guochao Nie, Professor Guangxi Key Laboratory of Agricultural Resources Chemistry and Biotechnology, Yulin Normal University, China, Tel: +86-17377071871;

E-mail: bccu518@163.com or bccu518@ylu.edu.cn

Yulin Yan, Professor, Department of Dermatology and Venereology, First Affiliated Hospital of Guangxi Medical University, China, Tel: +86-13978851236; E-mail:2637334542@qq.com

Keywords: MR imaging agent; Tumor; Nano liposomes; Free cholesterol; Nanovesicle

https://www.peertechz.com

Check for updates

\begin{abstract}
There are many patents for magnetic nanoparticles as tumor magnetic resonance imaging enhancers, but the gadolinium complexes commonly used in the clinic are difficult to target the diseased tissues, while nanoliposomes are ideal carriers for anti-tumor drugs. Owing to that the commonly used liposome particle size is too large, poor stability, the Cholesterol was used to increase the stability of nanoparticles or reduce their diameter. This foreign cholesterol may also have toxic side effects on patients. And the existing liquid film process cannot be large-scale production. The aim of this paper is to overcome the shortcomings of the prior art, then put forward a new method for preparing cholesterol-free tumor magnetic resonance imaging enhancer based on nano liposome encapsulation was proposed. We can obtain tumor magnetic resonance imaging enhancers with low toxicity and a good ability to cross biofilm. Finally, the facile fabrication was proved according to applications.
\end{abstract}

\section{Introduction}

For many tissue lesions, magnetic resonance imaging technology relies on the developer to improve the image clarity, especially for the diagnosis of tumor, without the developer, the clear image of the lesions cannot be obtained. The developed tumor MRI (Magnetic resonance imaging) imaging agents can be divided into four categories: Metal salt, metal chelates biomacromolecule preparation and microparticle preparation [1-5]. Among, magnetic nanoparticles have been used as magnetic resonance imaging agents, For example, Li Xiaojuan's team of Chongqing Medical University proposed the preparation method of magnetic resonance developer of chitosan coated $\mathrm{Fe}_{3} \mathrm{O}_{4}$ magnetic nanoparticles [6], in addition, the preparation method of gadolinium loaded chitosan nanoparticles as magnetic resonance imaging contrast agent proposed by Zhang Li of Shandong University [7]. However, there are some problems in these disclosed preparation methods of developer, for example, biocompatibility is not high, it is easily engulfed by macrophages, it does not have ideal internal circulation characteristics in blood, it is not easy to accumulate in specific tissues, at the same time, gadolinium complexes commonly used in clinic are usually toxic, and it is difficult to enter the lesion cells [8-10]. The drug encapsulated by nano liposome has good biocompatibility, low toxicity, the treatment effect is good, after surface targeted modification, 
it has the characteristics of active targeting tumor [11-16]. Therefor, nanoliposome is an ideal carrier for antitumor drugs, it has been used in clinical treatment, nano liposomes can be used to encapsulate magnetic complex to prepare improved developer [17-24]. However, in the research of Li Jing team [25] of Hunan Provincial People's Hospital and Wei Xin team [26] of Xinhua Hospital Affiliated to Medical College of Shanghai Jiaotong University on the application of liposome encapsulated tumor developer, the size of liposome is too large, poor stability, cholesterol is used to increase the stability of nanoparticles or reduce the diameter of nanoparticles, this foreign cholesterol may also bring side effects to patients, and the existing liquid membrane method cannot be mass-produced [27-35]. So the market needs to be cheap, low toxicity, and the ability to cross the biofilm is good, aiming at the defects of the existing technology, in this paper, we propose a method to prepare cholesterol free tumor MRI imaging agent based on nano liposome.

\section{Materials and methods}

\section{Technical proposal}

The preparation method of cholesterol free nano magnetic resonance developer was proposed, first, the solution a containing soluble protein is mixed with the solution B containing phospholipid to obtain the lipoprotein suspension $\mathrm{D}$, then , only protein suspension $\mathrm{D}$ and solution $\mathrm{C}$ containing soluble metal salts and / or soluble metal chelates were filtered by hydrophobic nanofiltration, react at 50, for A period of time, then, the organic solvent in the reaction product of the reaction is evaporated by A rotary evaporator, the colloid $\mathrm{F}$ was obtained, then the colloid was dispersed in pure water, nano emulsion $\mathrm{G}$ was obtained, cooling and drying of nano emulsion, finally, A fluffy powder is obtained, it is a cholesterol free tumor magnetic resonance imaging agent $\mathrm{F}$ encapsulated by nano liposomes.

\section{Preparation steps}

The specific preparation process and raw material combination are shown in Figure 1, which can be divided into eight steps.

The first step, the soluble protein was mixed with pure water at the mass ratio of 2.7-7.2:100, vortex 1-15 min, the scroll speed is $600-6000 \mathrm{rpm}$, the soluble protein is dissolved in pure water, solution a is obtained by dissolution, the soluble protein can be one or more mixtures of water-soluble animal protein, water-soluble plant protein, water-soluble fungal protein, water-soluble bacterial protein and water-soluble recombinant protein expressed by bacteria, the water-soluble animal protein can be any one or more mixtures of serum albumin, globulin, egg protein, casein, water-soluble protein of water-soluble protein of silkworm pupa, sericin and egg white protein, the water-soluble plant protein can be any one or more mixtures of water-soluble soybean protein, black soybean protein, rice protein, corn protein, wheat protein, ginseng water-soluble protein, mulberry leaf protein and protein lifting solution containing plant protein, the watersoluble bacterial protein and water-soluble fungal protein can be any one or more mixtures of water-soluble Rhizobium protein, the water-soluble recombinant protein expressed by the bacteria can be expressed by recombinant human serum albumin and / or soluble protein expressed by Escherichia coli.

In the second step, the solid-liquid ratio of lecithin and organic solvent was 1.5-4:100, and the vortex speed was 600$6000 \mathrm{rpm}$ for 1-15 min; Or the mixture of phospholipid and organic solvent was treated with ultrasonic for 1-15 min, the ultrasonic frequency was 5-150 Khz, the ultrasonic power was 5-1800 w, the phospholipid was dissolved in organic solvent, and the solution B was obtained. The phospholipid can be phospholipid glyceride or sphingomyelin, and the organic solvent can be any one or more mixtures of cyclohexane, chloroform, benzene, ether and petroleum ether.

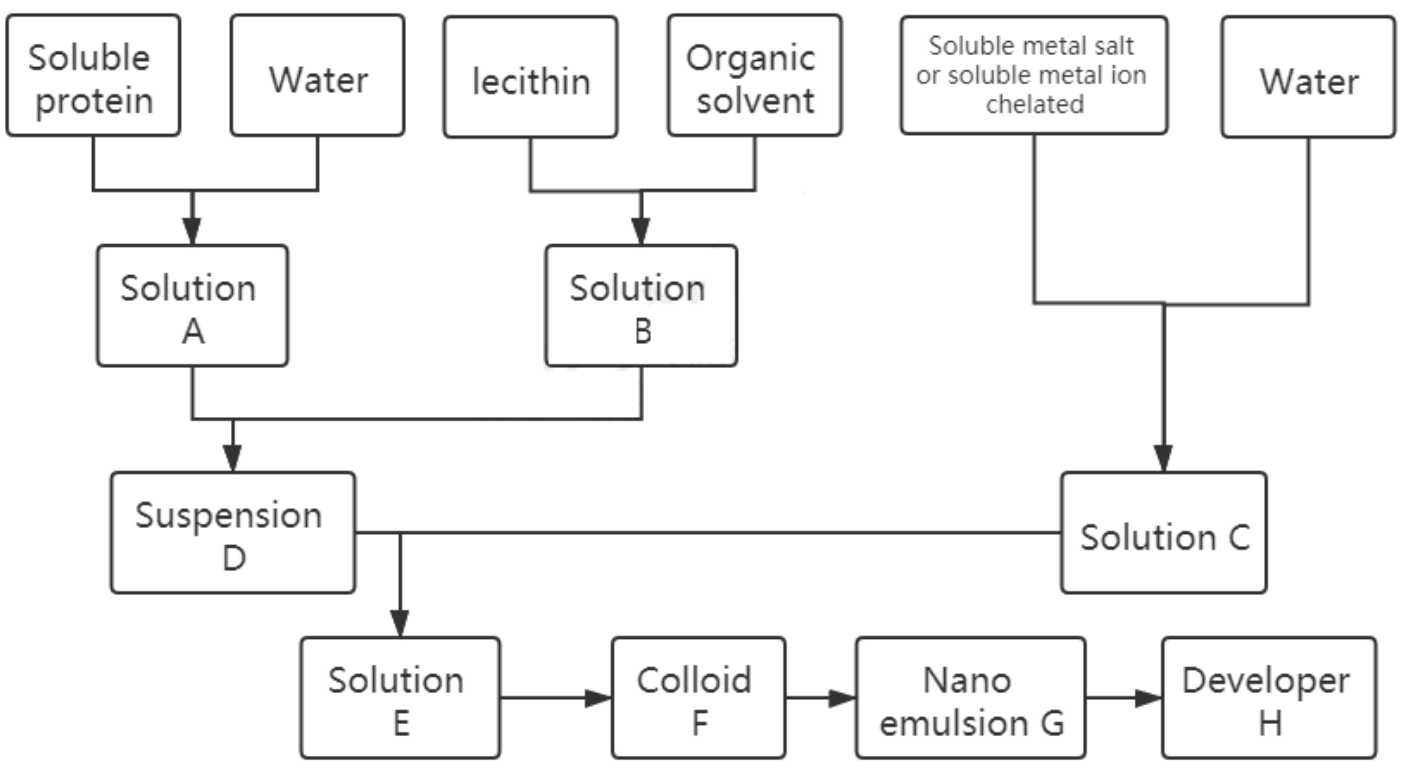


In the third step, the soluble metal salt or soluble metal ion chelate was added into the pure water, the vortex was vibrated for $1-15 \mathrm{~min}$, and the vortex speed was $600-6000 \mathrm{rpm}$; Or the soluble metal salt and / or soluble metal ion chelate were added into pure water and treated with ultrasonic for $1-15 \mathrm{~min}$. The ultrasonic frequency was 5-15 Khz and the ultrasonic power was 5-1800 w. After dissolution, solution C was obtained, and the concentration of metal ions in solution $C$ was $1-100 \mathrm{mg} / \mathrm{ml}$. The soluble metal salt can be any soluble salt of $\mathrm{Ti}^{3+}, \mathrm{Ni}^{2+}, \mathrm{Fe}^{3+}$, $\mathrm{Fe}^{2+}, \mathrm{V}^{4+}, \mathrm{CO}^{3+}, \mathrm{Cr}^{3+}, \mathrm{Mn}^{2+}, \mathrm{Cu}^{2+}, \mathrm{PR}^{3+}, \mathrm{Gd}^{3+}, \mathrm{Eu}^{3+}, \mathrm{Dy}^{3+}$ or a mixture of soluble salts of more than one metal ion, and the metal ion chelate can be any soluble salt of $\mathrm{Ti}^{3+}, \mathrm{Ni}^{2+}, \mathrm{Fe}^{3+}, \mathrm{Fe}^{2+}, \mathrm{V}^{4+}, \mathrm{C}_{0}{ }^{3+}$, $\mathrm{Cr}^{3+}, \mathrm{Mn}^{2+}, \mathrm{Cu}^{2+}, \mathrm{Pr}^{3+}, \mathrm{Gd}^{3+}, \mathrm{Eu}^{3+}, \mathrm{Dy}^{3+}$. A soluble chelate of any one ion or a mixture of soluble chelates of more than one metal ion, and the mixture of the soluble metal salt and soluble metal ion chelate can be mixed with the soluble salt of any one or more of the metal ions $\mathrm{Ti}^{3+}, \mathrm{Ni}^{2+}, \mathrm{Fe}^{3+}, \mathrm{Fe}^{2+}, \mathrm{V}^{4+}, \mathrm{Co}^{3+}, \mathrm{Cr}^{3+}, \mathrm{Mn}^{2+}$, $\mathrm{Cu}^{2+}, \mathrm{Pr}^{3+}, \mathrm{Gd}^{3+}, \mathrm{Eu}^{3+}, \mathrm{Dy}^{3+}$ and one or more of them A mixture of soluble chelates of more than one metalion.

In the fourth step, solution a was added to solution $\mathrm{B}$, the mass ratio of soluble protein in solution a to lecithin in solution B was 25-100:14-41, the vortex vibration was $3-15 \mathrm{~min}$, the vortex speed was $600-6000 \mathrm{rpm}$, and then the ultrasonic treatment was carried out for 10-60min, the ultrasonic frequency was 5-150 Khz, and the ultrasonic power was 5-1800 $\mathrm{w}$ to obtain lipoprotein suspension D.

In the fifth step, solution $\mathrm{C}$ was added to the lipoprotein suspension, the mass ratio of metal ions in solution $\mathrm{C}$ and lipoprotein in lipoprotein suspension D was 1.9-6.8:38-154, the vortex vibration was 5-15 $\mathrm{min}$, the vortex speed was $600-6000$ rpm, and then the suspension $\mathrm{E}$ was obtained by ultrasonic treatment for 10-30 min, the ultrasonic frequency was 5-150 $\mathrm{Khz}$, and the ultrasonic power was 5-1800 w.

In the sixth step, the suspension e was stirred at 40-60 ${ }^{\circ} \mathrm{C}$ for $1-10 h$, the stirring speed was $250-500 r p m$, and then the organic solvent of suspension $\mathrm{E}$ was evaporated by rotary evaporator to obtain colloidal substance F.

The seventh step is to add colloid $\mathrm{F}$ into the pure water according to the mass ratio of 1:5-10 and disperse the colloid in pure water by ultrasonic vibration, and obtain nano emulsion G.

In the eighth step, the nano emulsion is freeze-dried at -50 degrees Celsius to get the powder and the final product is obtained. The liposome encapsulated cholesterol free tumor magnetic resonance developer $\mathrm{H}$.

\section{Experiment and result analysis}

In order to verify the effect of the preparation method of nano liposome encapsulated cholesterol tumor MRI developer proposed in this paper, three different raw material combinations were selected for three implementation cases. As shown in Table 1, the preparation method in this paper was used for preparation, and the final product enhancer was analyzed for laboratory data.

\section{Particle size stability analysis}

The particle size stability of magnetic resonance developer is an important index to measure the contrast agent. The particle size of nano magnetic resonance developer directly affects the effect of magnetic resonance enhancement. The finished product of implementation case 1 is iron containing nano liposome tumor magnetic resonance imaging agent. First, it is refrigerated at $4^{\circ} \mathrm{C}$ in dark, and then dissolved in water after 30 days and 180 days. The particle size is determined. The results are shown in Figure 2, Table 2.

It can be seen from Figure 2 and Table 2 that the particle size of the iron containing nano tumor magnetic resonance developer in case 1 of this paper is basically unchanged after 30 days of storage, especially after 180 days of cold storage. The measurement results show that the particle size is still maintained at $80-90 \mathrm{~nm}$, indicating that the magnetic resonance developer prepared by this method has good stability. The particle size is not easily changed, and can be stored for a long time.

Table 1: Raw material combination table of nanoliposomes.

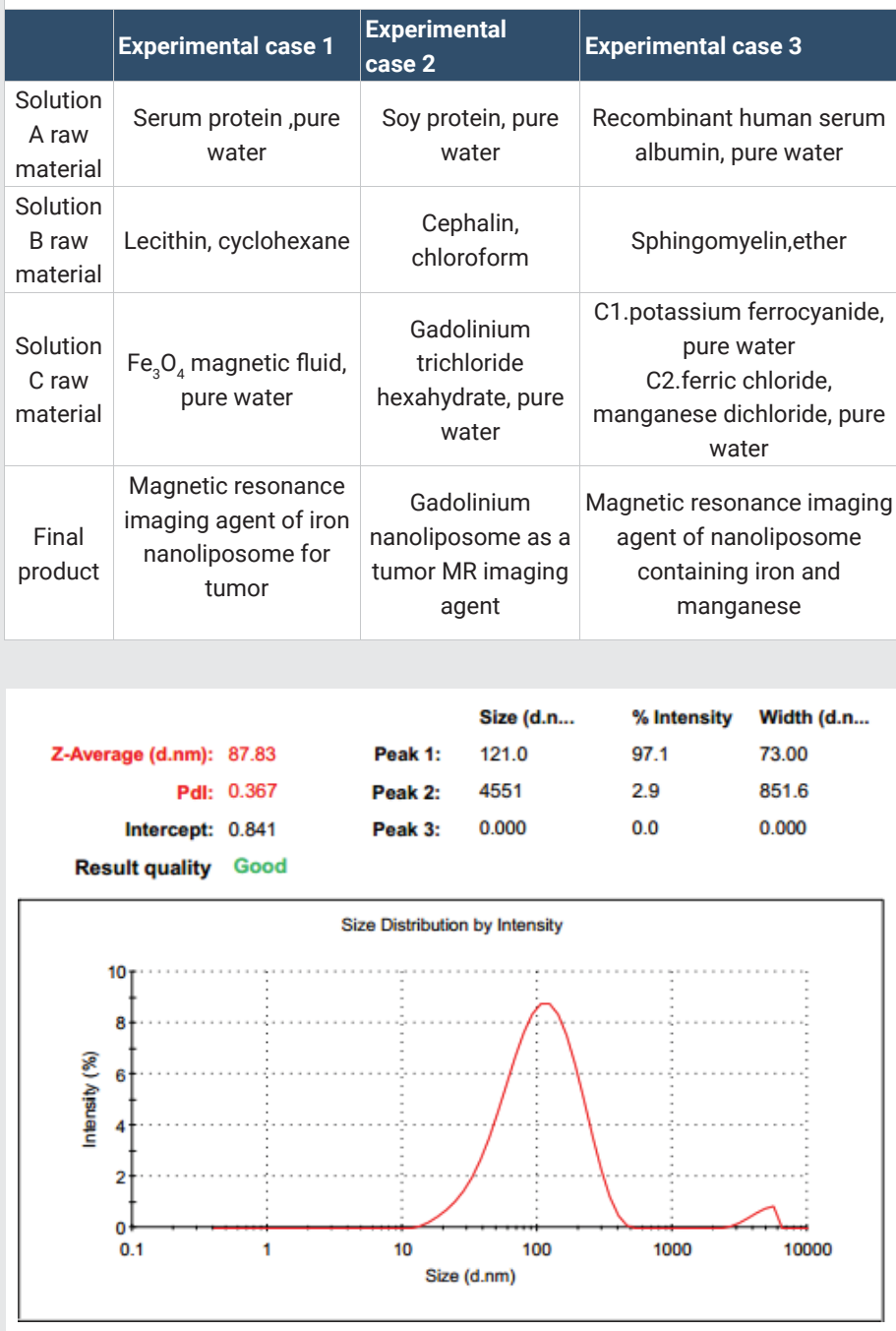

Figure 2: Particle size distribution map of magnetic resonance imaging agent containing iron nanoparticles for tumor (180 days later).

Citation: Zhang Z, Nie G, Deng Y, Song L, Wei W, et al. (2021) Nanovesicles of cholesterol-free enable malignant tumor-specific magnetic resonance imaging. J Clin Microbiol Biochem Technol 7(1): 014-019. DOI: https://dx.doi.org/10.17352/jcmbt.000046 


\section{Analysis of image enhancement effect}

The finished product of case $\mathbf{2}$ is gadolinium nanoliposome tumor magnetic resonance imaging agent. The nanoliposome is adjusted to different concentrations for in vitro tumor magnetic resonance imaging. The imaging situation, distribution, metabolic process and effect of the liposome are observed in Figure 3.

As shown in Figure 3, from top to bottom in Figure 3 is the in vitro tumor magnetic resonance imaging obtained by using water and adjusting the gadolinium containing nano liposome tumor magnetic resonance imaging agent in case 2 of this paper to $20 \mathrm{mg} / \mathrm{ml}, 10 \mathrm{mg} / \mathrm{ml}, 5 \mathrm{mg} / \mathrm{ml}, 2.5 \mathrm{mg} / \mathrm{ml}$ and 1.25 $\mathrm{mg} / \mathrm{ml}$ respectively. In Figure 3, the two circles on the left are the $\mathrm{T} 1$ weighted imaging results measured in parallel, and the two circles on the right are the T2 weighted imaging results measured in parallel. It can be seen from Figure 3 that the nano liposome tumor MRI developer prepared by the text has a good T1 and T2 weighted image enhancement effect on tumor MRI.

\section{Analysis of efficacy persistence}

The finished product of case 3 is the iron and manganese nanoliposome tumor MRI developer. It can be seen from Figures 4,5 that the enhancement agent has the strongest image enhancement effect on the tumor within 2-10 h, with the maximum gray value, the brightness of gray-scale image is the highest, and the pseudo color image is the reddest, maintaining a high tracer effect. After 12 hours, the gray value of tumor decreased significantly, and after 24 hours, no tracer was observed in vivo. The results show that the nano magnetic resonance imaging agent prepared by this method is

Table 2: Stability of tumor magnetic resonance imaging agent containing iron nanoliposomes.

\begin{tabular}{|c|c|c|}
\hline Index & 30day & 180day \\
\hline Particle size/nm & 77.88 & 87.83 \\
\hline
\end{tabular}

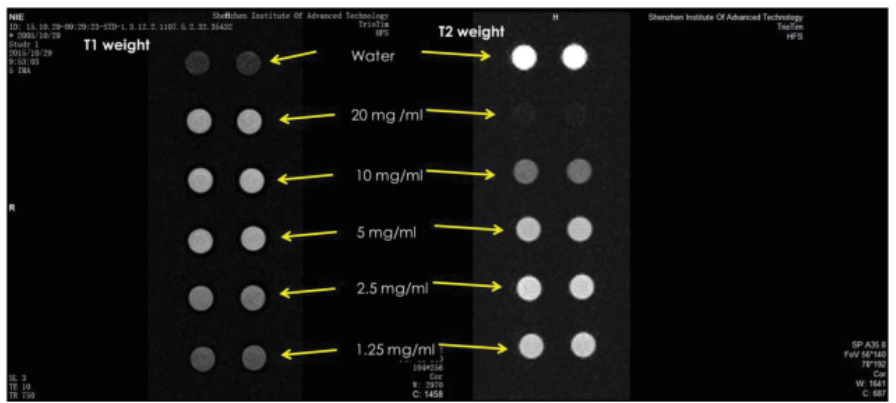

Figure 3: Enhanced effect of tumor magnetic resonance imaging in vitro.

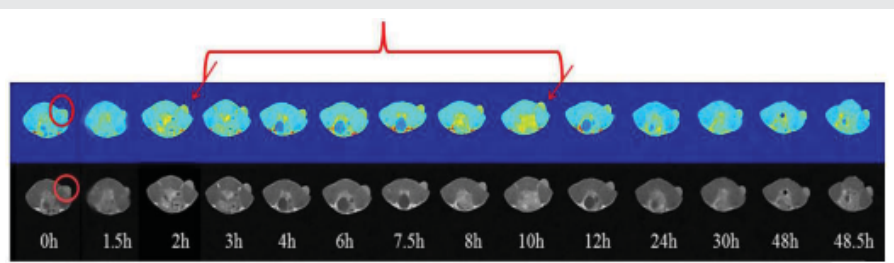

Figure 4: Enhancement effect of tumor nanometer magnetic resonance imaging enhancer in vivo.

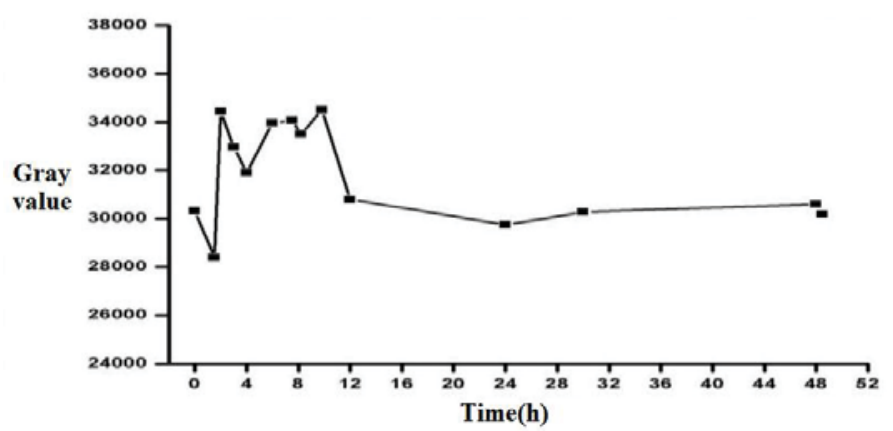

Figure 5: Gray value of enhancement effect of tumor nanometer magnetic resonance imaging enhancer in vivo.

suitable for clinical application in vivo, and the retention time is appropriate. It can be quickly discharged from the body after 24 hours, and there is no residue in the human body.

\section{Conclusions}

The preparation method proposed in this paper changes the existing preparation process of nano liposomes by reverse phase evaporation method. A cholesterol free tumor magnetic resonance imaging agent encapsulated by nano liposomes was prepared by using phospholipid and water-soluble protein as main raw materials, paramagnetic metal ions as chelating agent and stabilizer of liposomes, and cholesterol free biomembrane simulation assembly method.

The self-made method has the advantages of simple process, good tumor MRI enhancement effect, avoiding the introduction of cholesterol which is easy to cause arteriosclerosis, coronary heart disease and other injuries to human body, overcoming the problems of poor stability and difficult large-scale industrial production of traditional nano liposome preparation method, suitable for clinical application in vivo, and can be quickly discharged out of the body without residue The prepared MR imaging agent has the advantages of low cost, low toxicity and good ability to cross biofilm, which has a good application prospect.

\section{Fund projects}

National Natural Science Foundation of China (grant numbers 81660508), Guangxi Science and Technology Key Research Project (grant numbers Guike AB17195076, AB16380153),Guangxi Innovation and Development Major Project (NO.GUIKEJIZI (2020) 302).

\section{References}

1. Lijiang H, Wenxian $\mathrm{G}$ (2013) Research progress of targeting magnetic resonance imaging agent for ultra small superparamagnetic iron oxide particles. Chinese Cancer Clinic 40: 423-426.

2. Hua A (2008) Application of self assembled magnetic nanomaterials in magnetic resonance imaging. Chinese chemical society. Proceedings of the $26^{\text {th }}$ Annual Conference of Chinese chemical society, frontier branch of functional polymer science [C]. Chinese Chemical Society: Chinese chemical society 1

3. Shaowei B (2015) Design, synthesis and properties of fluoro-19 magnetic resonance / fluorescence bimodal developer. Nanhua University.

Citation: Zhang Z, Nie G, Deng Y, Song L, Wei W, et al. (2021) Nanovesicles of cholesterol-free enable malignant tumor-specific magnetic resonance imaging. J Clin Microbiol Biochem Technol 7(1): 014-019. DOI: https://dx.doi.org/10.17352/jcmbt.000046 
4. Zhenpeng Z (2014) Study on interstitial magnetic resonance lymphography of popliteal lymph node metastasis of dextran DTPA GD Rabbit Thigh tumor Qingdao University.

5. Haiyan L (2013) Study on bone marrow perfusion based on dynamic enhanced magnetic resonance imaging. Harbin Institute of technology.

6. Xiaojuan L, Xiyuan Y, Shenggeng W, Weicheng Z, Zengtao Y (2019) Preparation of chitosan coated $\mathrm{Fe} 304$ magnetic nanoparticles and experimental study on magnetic resonance imaging. Chinese society of ultrasonic medical engineering. Proceedings of the 10th National Conference on ultrasound therapy and BIOEFFECTIVE medicine [C]. Chinese society of ultrasonic medical engineering: Chinese Society of Ultrasonic Medical Engineering 2019: 1.

7. Yongjun L, Zhijin C, Na Z (2011) Application of novel gadolinium nanocarriers in liver targeted molecular magnetic resonance imaging contrast agents. Journal of Chinese Pharmaceutical Sciences 20: 105-117.

8. Li Z (2014) Study on gadolinium loaded chitosan nanoparticles as contrast agent for magnetic resonance imaging for tumor diagnosis. Shandong University.

9. Qingchun Z (2016) Literature analysis of 189 cases of adverse reactions induced by gadopentadine. Anti infective pharmacy 13: 118-120.

10. Jun Z, Yuntao H, Xunlun S (2010) Effect of manganese ion as image enhancement agent on nervous system function. International Journal of Ophthalmology 10: 905-907.

11. Yarce CJ, Alhajj MJ, Sanchez JD, Oñate-Garzón J, Salamanca CH (2020) Development of Antioxidant-Loaded Nanoliposomes Employing Lecithins with Different Purity Grades. Molecules (Basel, Switzerland) 25: 5344. Link: https://bit.ly/3jypUJO

12. Sepanta H, Chun X, Laurence JW (2021) Impact of photobiomodulation using four diode laser wavelengths of on cationic liposome gene transfection into pre-osteoblast cells. Journal of Photochemistry \& Photobiology B: Biology 215: 112108. Link: https://bit.ly/3jy53G9

13. Veloso RSS, Andrade RGD, Castanheira EMS (2021) Review on the advancements of magnetic gels: towards multifunctional magnetic liposomehydrogel composites for biomedical applications. Advances in Colloid and Interface Science 288: 102351. Link: https://bit.ly/3cOVbGW

14. Diego B, Jiménez MEP, Dos Santos C, Corrêa APF, Brandelli A (2021) Microbia bioconversion of feathers into antioxidant peptides and pigments and their liposome encapsulation. Biotechnol Lett. Link: https://bit.ly/3rAclXI

15. Vu MT, Trang NT, Le-Buu PT, Ngoc Hoi N, Hai ND (2020) Development and Characterization of Soy Lecithin Liposome as Potential Drug Carrier Systems for Codelivery of Letrozole and Paclitaxel. Journal of Nanomaterials 2020 Link: https://bit.ly/3oWej8k

16. Naumenko VA, Vodopyanov SS, Vlasova KY, Potashnikova DM, Melnikov PA (2020) Intravital imaging of liposome behavior upon repeated administration: A step towards the development of liposomal companion diagnostic for cancer nanotherapy. J Control Release 330: 244-256. Link: https://bit.ly/3jld4Zz

17. Heze G, Zequan J, Sheng S, Kang S, Hongjing D (2015) Preparation of polymer / magnetic nanoparticles composite microcapsule acoustic / magnetic dual developer by self-assembly method. Polymer disciplinary committee of Chinese chemical society. Abstracts of papers of 2015 national polymer academic symposium topic I: high molecular assembly and supramolecular system. Polymer disciplinary committee of Chinese Chemical Society: Chinese Chemical Society 2015: 1.

18. Kannan S, Solomon A, Krishnamoorthy G, Marudhamuthu M (2021) Liposome encapsulated surfactant abetted copper nanoparticles alleviates biofilm mediated virulence in pathogenic Pseudomonas aeruginosa and MRSA. Sci Rep 11: 1102. Link: https://bit.ly/3jxiHcD
19. Huiling S, Hart SL, Du Z (2021) Assembly strategy of liposome and polymer systems for siRNA delivery. Int J Pharm 592: 120033. Link: https://bit.ly/3pONyQc

20. Mourtas S, Mavroidi B, Marazioti A, Kannavou M, Sagnou M, et al. (2020) Liposomes Decorated with 2-(4'-Aminophenyl)benzothiazole Effectively Inhibit $A \beta<$ sub $>1-42</$ sub $>$ Fibril Formation and Exhibit in Vitro Brain-Targeting Potential. Biomacromolecules 21: 4685-4698. Link: https://bit.ly/3p2wzNe

21. Regenold M, Jessica S, Siniscalchi E, Dunne M, Luca C, et al. (2020) Determining critical parameters that influence in vitro performance characteristics of a thermosensitive liposome formulation of vinorelbine. Journal of Controlled Release 328: 551-561. Link: https://bit.ly/3qgh2Lr

22. Aibani N, Callan B, Khan TN (2019) Liposome mimicking polymersomes; A comparative study of the merits of polymersomes in terms of formulation and stability. Int J Pharm X 2: 100040. Link: https://bit.ly/3q4cqYB

23. Dana $P$, Bunthot $S$, Suktham $K$, Surassmo $S$, Yata T, et al. (2020) Active targeting liposome-PLGA composite for cisplatin delivery against cervical cancer. Colloids and Surfaces B: Biointerfaces 196: 111270. Link: https://bit.ly/2Z1qdTI

24. Che J, Najer A, Blakney AK, McKay PF, Bellahcene M, et al. (2020) Neutrophils Enable Local and Non-Invasive Liposome Delivery to Inflamed Skeleta Muscle and Ischemic Heart. Advanced Materials 32: 2003598. Link: https://bit.ly/3p52wVf

25. Jing L, Xu W, Qian P, Chenxu W, Fan Y (2020) Resveratrol loaded liposome encapsulated mesoporous carbon nanotubes for targeted and near infrared laser triggered chemotherapy / photothermal synergistic tumor therapy. Acta Laser Biology 29: 550-560

26. Xin W, Zhenhao H, Ying X, Linlin Z (2020) Preparation of (131) I-labeled sorafenib nanoliposomes and its therapeutic effect on undifferentiated thyroid cancer. Chinese Journal of Modern Applied Pharmacy 37: 2697-2702.

27. Jahanfar S, Gahavami M, Darani KK, Jahadi M (2020) Antioxidant Activities of Free and Liposome-Encapsulated Green tea extracts on canola oil oxidation stability. Journal of the American Oil Chemists' Society 97: 1343-1354. Link: https://bit.ly/3rAeLdZ

28. Even-Or O, Avniel-Polak S, Barenholz Y, Nussbaum G (2020) The cationic liposome CCS/C adjuvant induces immunity to influenza independently of the adaptor protein MyD88. Hum Vaccin Immunother 16: 3146-3154. Link: https://bit.ly/3aQJz3k

29. Wu S, Lin X, Cui X (2020) Effect of Liposome-Encapsulated Zoledronic Acid on Microenvironment of Hepatocellular Carcinoma May Depend on the Ratio Between M1 and M2 Polarized Macrophages. Bull Exp Biol Med 170: 69-74. Link: https://bit.ly/3rAfhZt

30. Yin H, Du B, Chen Y, Song N, Li Z, et al. (2020) Dual-encapsulated biodegradable $3 \mathrm{D}$ scaffold from liposome and waterborne polyurethane for local drug control release in breast cancer therapy. J Biomater Sci Polym Ed 31: 2220-2237. Link: https://bit.ly/2MMc8qR

31. Kuchyanov AS, Mikerin SL, Adichtchev SV, Al'Qaisi AHS, Zaitseva YuV (2020) Development of the Spaser-in-Liposome Complexes for Theranostical Application. Optoelectronics, Instrumentation and Data Processing 56: 304 309. Link: https://bit.ly/2NdNdwo

32. Penoy N, Grignard B, Evrard B, Piel G (2020) A supercritical fluid technology for liposome production and comparison with the film hydration method. Int $\mathrm{J}$ Pharm 592: 120093. Link: https://bit.ly/36VRrzL

33. Penoy N, Grignard B, Evrard B, Piel G (2020) A supercritical fluid technology for liposome production and comparison with the film hydration method. Int $J$ Pharm 592: 120093. Link: https://bit.ly/36VRrzL

Citation: Zhang Z, Nie G, Deng Y, Song L, Wei W, et al. (2021) Nanovesicles of cholesterol-free enable malignant tumor-specific magnetic resonance imaging. J Clin Microbiol Biochem Technol 7(1): 014-019. DOl: https://dx.doi.org/10.17352/jcmbt.000046 
34. Liu J, Liu J, Lu Z,Xu X (2021) Theoretical analysis of annular film flow evaporation inside microfin tube. International Journal of Heat and Mass Transfer 165: 120611. Link: https://bit.ly/2LxWgrj
35. Ripoll L, Navarro González S, Legnaioli S, Palleschi V, Hidalgo M (2021) Evaluation of Thin Film Microextraction for trace elemental analysis of liquid samples using LIBS detection. Talanta 223: 121736. Link: https://bit.ly/3pZhYDA
Discover a bigger Impact and Visibility of your article publication with Peertechz Publications

\section{Highlights}

* Signatory publisher of ORCID

* Signatory Publisher of DORA (San Francisco Declaration on Research Assessment)

- Articles archived in worlds' renowned service providers such as Portico, CNKI, AGRIS, TDNet, Base (Bielefeld University Library), CrossRef, Scilit, J-Gate etc.

* Journals indexed in ICMJE, SHERPA/ROMEO, Google Scholar etc.

* OAI-PMH (Open Archives Initiative Protocol for Metadata Harvesting)

* Dedicated Editorial Board for every journal

* Accurate and rapid peer-review process

* Increased citations of published articles through promotions

* Reduced timeline for article publication

Submit your articles and experience a new surge in publication services

(https://www.peertechz.com/submission).

Peertechz journals wishes everlasting success in your every endeavours.

Copyright: @ 2021 Zhang Z, et al. This is an open-access article distributed under the terms of the Creative Commons Attribution License, which permits unrestricted use distribution, and reproduction in any medium, provided the original author and source are credited.

Citation: Zhang Z, Nie G, Deng Y, Song L, Wei W, et al. (2021) Nanovesicles of cholesterol-free enable malignant tumor-specific magnetic resonance imaging. J Clin Microbiol Biochem Technol 7(1): 014-019. DOI: https://dx.doi.org/10.17352/jcmbt.000046 